\title{
Maintenance of memory T cells in the bone marrow: survival or homeostatic proliferation?
}

\section{Francesca Di Rosa}

Six years ago, Radbruch and colleagues discussed in Nature Reviews Immunology (Organization of immunological memory by bone marrow stroma. Nat. Rev. Immunol. 10, 193-200 (2010)) $)^{1}$ how distinct stromal cell subsets in the bone marrow can support the lifelong persistence of plasma cells and memory $\mathrm{T}$ cells. These authors proposed that the bone marrow might serve as a depot for resting noncirculating memory T cells. Furthermore, they discussed how memory T cells might be maintained in the bone marrow by survival factors, such as interleukin-7 (IL-7), as opposed to by proliferative factors, such as IL-15. This view was in contrast with the largely accepted notion at the time that recirculating memory T cells are maintained by a homeostatic equilibrium between proliferation and death long after antigen clearance ${ }^{2}$. Furthermore, it did not accommodate previous data concerning the proliferation $^{3,4}$ and recirculation ${ }^{5,6}$ of memory $\mathrm{CD}^{+} \mathrm{T}$ cells in the bone marrow.

Recently, the idea that was originally proposed in Nature Reviews Immunology ${ }^{1}$ was revived by the identification of quiescent, non-migratory tissue-resident memory $\mathrm{T}\left(\mathrm{T}_{\mathrm{RM}}\right)$ cells in the skin, gut and other organs ${ }^{7}$. Indeed, Radbruch et al. hypothesized that bone marrow memory $\mathrm{T}$ cells might share several features with $\mathrm{T}_{\mathrm{RM}}$ cells, and they suggested that their previous and newly generated findings supported this concept ${ }^{8,9}$. However, it might be misleading to chiefly consider bone marrow memory $\mathrm{T}$ cells as non-circulating, non-dividing cells.

Experiments using Ki67 staining in mice and humans have shown that, at any given time-point, $95-98 \%$ of memory $\mathrm{CD}^{+} \mathrm{T}$ cells in the bone marrow are in the G0 phase of the cell cycle ${ }^{8,9}$. Of the remaining cells, some are in the G1 interval, and a few (that is, 0.2$1.7 \%$ ) are actively proliferating in $\mathrm{S} / \mathrm{G} 2 / \mathrm{M}^{3,8,9}$. However, this still means that the proportion of memory $\mathrm{CD}^{+} \mathrm{T}$ cells proliferating in the bone marrow is reproducibly two- to fourfold higher than the proportions (that is, $0.05-0.80 \%$ ) proliferating in the spleen, lymph nodes or blood ${ }^{3,8,9}$. This is true also when cell division is measured for one or more days. For example, in a 3 day-bromodeoxyuridine
(BrdU)-labelling analysis, the average frequency of dividing antigen-specific memory $\mathrm{CD}^{+} \mathrm{T}$ cells was $4 \%$ in the bone marrow and $2 \%$ in the spleen ${ }^{4}$. Moreover, when carboxyfluorescein succinimidyl ester (CFSE)-labelled antigen-specific memory CD8 ${ }^{+} \mathrm{T}$ cells were transferred into non-immunized animals, they showed higher rates of proliferation in the bone marrow than in the spleen and lymph nodes ${ }^{3,10}$. In general, the data concerning memory $\mathrm{CD}^{+} \mathrm{T}$ cell cycling in the bone marrow are all in agreement. However, memory $\mathrm{CD} 4^{+} \mathrm{T}$ cell proliferation requires further investigation, as antigen-specific cells have not been examined in the bone marrow ${ }^{11}$.

Despite the apparent consistency of the data concerning memory CD8 ${ }^{+} \mathrm{T}$ cells, their interpretations differ. Radbruch's group proposes that these data suggest similarity between bone marrow memory $\mathrm{CD}^{+} \mathrm{T}$ cells and peripheral $\mathrm{T}_{\mathrm{RM}}$ cells, reinforcing the concept that a resting non-proliferative state following antigen clearance is the hallmark of memory $\mathrm{CD}^{+}$ T cells ${ }^{8,9}$. These authors suggest that the number of memory $\mathrm{CD} 8^{+} \mathrm{T}$ cells proliferating in the bone marrow is negligible and may have been overestimated owing to a BrdU-related artefact ${ }^{9}$. They also showed by RNA microarray analysis that bone marrow memory $\mathrm{CD}^{+}$ $\mathrm{T}$ cells resembled their spleen counterparts and that both had overtly different transcriptomes from memory $\mathrm{CD}^{+} \mathrm{T}$ cells stimulated in vitro ${ }^{9}$. Moreover, they have suggested that bone marrow memory $\mathrm{CD}^{+} \mathrm{T}$ cells are sessile, as up to $60 \%$ of them express CD69, a molecule that in $\mathrm{CD}^{+} \mathrm{T}$ cells is essential for retention in the bone marrow ${ }^{8,9}$. Finally, they suggest that the colocalization of bone marrow memory $\mathrm{CD}^{+} \mathrm{T}$ cells with IL-7-producing stromal cells supports the idea of IL-7-driven survival of memory $\mathrm{CD}^{+} \mathrm{T}$ cells in the absence of proliferation'.

However, it could be argued that although the frequency of memory CD8 ${ }^{+} \mathrm{T}$ cells that are dividing in the bone marrow is low, the absolute numbers of proliferating memory $\mathrm{CD}^{+}$ $\mathrm{T}$ cells is much higher in the bone marrow than in the spleen and lymph nodes ${ }^{3,4}$. As regards BrdU-related artefacts, they may occur at high BrdU doses ${ }^{9}$ but seem uncommon at the standard BrdU dose that was used in bone marrow $T$ cell studies ${ }^{3,4,12}$. Notably, recent adoptive transfer experiments in genetically modified mice have shown that IL-15 in the bone marrow promotes proliferation and inhibits interleukin-7 receptor subunit- $\alpha$ (IL-7R $\alpha$ ) expression in memory CD8 ${ }^{+} \mathrm{T}$ cells, independently of antigen co-transfer or treatment with innate receptor agonists ${ }^{13}$. In respect to molecular data ${ }^{9}$, it is perhaps not surprising that transcription profiles were highly diverse when comparing ex vivo-isolated and in vitrostimulated cells; besides, some differences between freshly obtained spleen and bone marrow $\mathrm{CD} 44^{\text {hi }} \mathrm{CD} 8{ }^{+} \mathrm{CD} 3^{+} \mathrm{T}$ cells might have been missed owing to the cell sorting strategy. For instance, IL-7Ra ${ }^{\text {hi }}$, but not IL-7R $\alpha^{\text {low }}$, T cells were selected for analysis, and yet IL-7Ra ${ }^{\text {low }}$ $\mathrm{T}$ cells are enriched in the bone marrow ${ }^{8,13}$, reflecting in vivo exposure to IL-15 (REF. 13). Moreover, global transcription data, CD69 expression profiles and colocalization in tissue sections do not address in vivo T cell migration. In fact, in situ-labelling studies and parabiosis experiments have shown that memory $\mathrm{T}$ cells do recirculate to and from the bone marrow ${ }^{5,6}$.

In conclusion, the available evidence supports the view that the bone marrow is a 'stopping point' where recirculating memory $\mathrm{CD}^{+}$ $\mathrm{T}$ cells are stimulated to proliferate before continuing to move around the body $\mathrm{y}^{3,4,12,13}$. Notably, lodging into the bone marrow is a competitive process among memory T cells ${ }^{14}$, which is an element to be considered especially in interpretation of adoptive transfer data $^{11,14}$. Furthermore, reported diversities in the repertoire of antigen specificity between human bone marrow and blood memory $\mathrm{CD}^{+} \mathrm{T}$ cells after in vitro restimulation ${ }^{8}$ might reflect several features, including: differences in $\mathrm{T}$ cell recruitment into the bone marrow, undetected ongoing responses against common pathogens (for example, Candida albicans and Cytomegalovirus) and differences between in vitro and in vivo responses. Finally, recent parabiosis experiments demonstrated that a small percentage (up to 5\%) of memory $\mathrm{CD}^{+} \mathrm{T}$ cells in the spleen and lymph nodes are non-migratory ${ }^{15}$. Therefore, it is possible that a minor population of memory $\mathrm{CD}^{+}$ $\mathrm{T}$ cells in the bone marrow (as opposed to the majority) might be sessile, but direct evidence for this is lacking at the moment.

Francesca Di Rosa is at the Institute of Molecular Biology and Pathology, Consiglio Nazionale delle Ricerche, c/o Department of Molecular Medicine, Sapienza University, viale Regina Elena 291, Rome 00161, Italy. francesca.dirosa@uniroma1.it Published online 21 Mar 2016 


\section{CORRESPONDENCE}

1. Tokoyoda, K., Hauser, A. E., Nakayama, T. \& Radbruch, A. Organization of immunological memory by bone marrow stroma. Nat. Rev. Immunol. 10, 193-200 (2010).

2. Boyman, O., Letourneau, S., Krieg, C. \& Sprent, J. Homeostatic proliferation and survival of naive and memory T cells. Eur. J. Immunol. 39, 2088-2094 (2009).

3. Becker, T. C., Coley, S. M., Wherry, E. J. \& Ahmed, R. Bone marrow is a preferred site for homeostatic proliferation of memory CD8 T cells. J. Immunol. 174, 1269-1273 (2005).

4. Parretta, E. et al. CD8 cell division maintaining cytotoxic memory occurs predominantly in the bone marrow. J. Immunol. 174, 7654-7664 (2005).

5. Pabst, R., Miyasaka, M. \& Dudler, L. Numbers and phenotype of lymphocytes emigrating from sheep bone marrow after in situ labelling with fluorescein isothiocyanate. Immunology 59, 217-222 (1986).

6. Klonowski, K. D. et al. Dynamics of blood-borne CD8 memory T cell migration in vivo. Immunity $\mathbf{2 0}$ 551-562 (2004)
7. Gebhardt, T., Mueller, S. N., Heath, W. R. \& Carbone, F. R. Peripheral tissue surveillance and residency by memory T cells. Trends Immunol. 34 27-32 (2013).

8. Okhrimenko, A. et al. Human memory T cells from the bone marrow are resting and maintain longlasting systemic memory. Proc. Natl Acad. Sci. USA 111, 9229-9234 (2014).

9. Sercan Alp, O. et al. Memory CD8 + T cells colocalize with IL-7+ stromal cells in bone marrow and rest in terms of proliferation and transcription Eur. J. Immunol. 45, 975-987 (2015).

10. Lin, G. H., Snell, L. M., Wortzman, M. E., Clouthier, D. L. \& Watts, T. H. GITR-dependent regulation of 4-1BB expression: implications for $\mathrm{T}$ cell memory and anti-4-1BB-induced pathology. J. Immunol. 190, 4627-4639 (2013).

11. Tokoyoda, K. et al. Professional memory CD4+ $T$ lymphocytes preferentially reside and rest in the bone marrow. Immunity 30, 721-730 (2009).

12. Parretta, E. et al. Kinetics of in vivo proliferation and death of memory and naive CD8 T cells: parameter estimation based on 5-bromo-2'deoxyuridine incorporation in spleen, lymph nodes, and bone marrow. J. Immunol. 180, 7230-7239 (2008).

13. Quinci, A. C. et al. IL-15 inhibits IL-7R $\alpha$ expression by memory-phenotype CD8 ${ }^{+} \mathrm{T}$ cells in the bone marrow. Eur. J. Immunol. 42, 1129-1139 (2012)

14. Di Rosa, F. \& Santoni, A. Memory T-cell competition for bone marrow seeding. Immunology 108 296-304 (2003).

15. Schenkel, J. M., Fraser, K. A. \& Masopust, D. Cutting edge: resident memory CD8 T cells occupy frontline niches in secondary lymphoid organs. J. Immunol.

192, 2961-2964 (2014).

\section{Acknowledgements}

The author thanks A. Hayday, A. Santoni, G. Matarese, R. Pabst, J. Hiscott, T. Gebhardt and P. Matzinger for discussion.

Competing interests statement

The author declares no competing interests. 